\title{
Cuidado de enfermagem no adoecimento por acidente vascular encefálico: revisão integrativa da literatura brasileira
}

Nursing care regarding complications of stroke: an integrative review of Brazilian literature

\author{
Cuidado de enfermería en el padecimiento de accidente cerebrovascular: \\ revisión integrativa de la literatura brasileña
}

Samia Jardelle Costa de Freitas Maniva ${ }^{1}$, Consuelo Helena Aires de Freitas ${ }^{2}$

\section{RESUMO}

Revisão integrativa que objetivou analisar o conhecimento acerca do cuidado de enfermagem no adoecimento por Acidente Vascular Encefálico na base de dados LILACS. Os critérios de elegibilidade dos artigos foram os seguintes: correspondência aos termos "cuidado" e "acidente vascular encefálico"; publicação em língua portuguesa; disponibilidade de texto completo; ano de publicação no período de 2000 a 2011. Encontraram-se vinte publicações cujos dados foram coletados por meio de formulário. A análise ocorreu mediante leituras analítica e interpretativa. Como foco dos estudos sobressaíram a problemática da dependência do paciente e o papel desempenhado pelo cuidador familiar; a compreensão da vivência, experiências e sentimentos do cuidador familiar; e o impacto da doença na família. Percebeu-se a importância do preparo do cuidador familiar para a execução dos cuidados no domicílio. O enfermeiro é chamado a desempenhar o cuidado com vistas a ensinar a família a cuidar do paciente e ao autocuidado.

Descritores: Acidente Cerebral Vascular; Enfermagem; Cuidados de Enfermagem.

\section{ABSTRACT}

The objective of this integrative review was to analyze the knowledge regarding nursing care of individuals experiencing stroke complications present in the LILACS database. The criteria for the eligibility were: consistency with the terms "cuidado" (care) and "acidente vascular encefálico" (stroke); published in Portuguese; available in full-text; and published between 2000 and 2011. Twenty articles were found, and the data were collected using a form created for this purpose. The analysis was performed through an analytical and interpretative reading. Most studies focused on the problem of patient dependence and the role of family caregivers; understanding the experiences and feelings of the family caregiver; and the impact of the disease on the family. It was observed that it is important to prepare the family caregiver to provide home care. Nurses are called on to teach the family how to take care of the patient and instruct the patient regarding self-care.

Descriptors: Stroke; Nursing; Nursing Care.

\section{RESUMEN}

Revisión integrativa objetivando analizar el conocimiento respecto del cuidado de enfermería en el padecimiento de Accidente Cerebrovascular en base de datos LILACS. Los criterios de inclusión de artículos fueron: correspondencia con los términos "cuidado" y "accidente cerebrovascular"; publicación en portugués; disponibilidad del texto completo; año de publicación entre 2000 y 2011. Se encontraron 20 publicaciones cuyos datos fueron recolectados mediante formulario. El análisis se efectuó a partir de lecturas analíticas e interpretativas. Como foco de los estudios sobresalieron la problemática de la dependencia del paciente y el papel desempeñado por el cuidador familiar, la comprensión de vivencias, experiencias y sentimientos del cuidador familiar y el impacto familiar de la enfermedad. Se percibió la importancia de la preparación del cuidador familiar para ejecutar los cuidados domiciliarios. El enfermero es llamado a desempeñar su atención apuntando a enseñar a la familia a cuidar del paciente y fomentar el autocuidado.

Descriptores: Accidente Cerebrovascular; Enfermería; Atención de Enfermería.

\footnotetext{
${ }^{1}$ Enfermeira. Discente do Pós-Graduação Cuidados Clínicos Acadêmico Cuidados Clínicos em Saúde e Enfermagem, nível Mestrado, da Universidade Estadual do Ceará (UECE). Fortaleza, CE, Brasil. E-mail: samia jardelle@yahoo.com.br.

${ }^{2}$ Enfermeira, Doutora em Enfermagem. Professora Adjunta da UECE. Fortaleza, CE, Brasil. E-mail: consueloaires@yahoo.com.br.
} 


\section{INTRODUÇÃO}

Como disciplina e profissão, a enfermagem tem reunido esforços no intuito de desenvolver e fortalecer um corpo de conhecimentos científicos que the é próprio e compatível com as ideias da natureza da enfermagem com enfoque no ser humano e no cuidado, de modo a superar o modelo tradicional médico-científico. Para tanto, observa-se o número crescente de estudos entre enfermeiros centrados nos fenômenos da enfermagem.

$\mathrm{Na}$ busca de conhecimento científico enfrentam-se constantes desafios, sobretudo para a promoção da melhoria do cuidado. Deste modo, as pesquisas na Prática Baseada em Evidências (PBE), junto a assistência à saúde, têm sido encorajadas nos diversos níveis de atenção, contribuindo para o aprofundamento do conhecimento do tema investigado(1).

As pesquisas em enfermagem voltadas para a prática clínica em situações de adoecimento decorrente do Acidente Vascular Encefálico (AVE) têm se evidenciado entre as temáticas estudadas pela profissão. Compõem questões de grande impacto no cuidado à saúde. Atualmente, as doenças cerebrovasculares são consideradas uma das maiores causas de mortalidade e morbidade em todo o mundo. Elas representam a terceira causa mais comum de morte nos países em desenvolvimento, perdendo apenas para a doença coronariana e para o câncer. Ademais, são a principal causa de incapacidade entre adultos(2). No Brasil, a depender do ano e estado da federação, a doença situase entre a primeira e a terceira causa de mortalidade ${ }^{(3)}$.

Assim, as pesquisas no âmbito das doenças cerebrovasculares tornam-se fundamentais para alicerçar o enfermeiro no cotidiano da sua prática, fornecendo subsídios para auxiliar no entendimento das relações envolvidas no processo de adoecimento, inerente ao paciente e à família. Em termos epidemiológicos, a importância de tais doenças é outro aspecto a ser destacado, em face do aumento da longevidade da população e do incremento das doenças crônico-degenerativas.

No contexto de adoecimento por AVE, três personagens sobressaem de forma compartilhada: o paciente, a família e o enfermeiro, os quais interagem num espaço de encontro, que pode ser o hospital ou o domicílio. Para cuidar em plenitude, o enfermeiro precisa conhecer o ser cuidado, compreender seu mundo subjetivo interior, bem como suas carências exteriores e visíveis; aliar conhecimento técnico/científico, senso ético, solidário e estético ${ }^{(4)}$.

Com base nessas considerações, o cuidado à pessoa em situação de adoecimento por AVE requer uma abordagem ampliada que leve em conta a pessoa e sua realidade, na perspectiva de um cuidado integral que transcenda a dimensão física e contemple, inclusive, políticas públicas direcionadas à promoção da saúde e à prevenção dos fatores de risco para AVE. Dessa maneira, espera-se retardar o desenvolvimento da doença, tendo em vista seu impacto social para a vida das pessoas e suas famílias.

Ser doente pode representar para o homem viver uma vida diferente, que o exclui das atividades e papéis sociais até então desempenhados, o faz sentir impotente, aumenta seus medos e inseguranças e ameaça sua própria integridade ${ }^{(5)}$. Esta situação é mais grave quando a doença se manifesta de forma abrupta e apresenta elevado potencial para sequelas e incapacidades.

Portanto, o ato de cuidar em si possui uma dimensão complexa em virtude da sua singularidade, dinamicidade e interatividade ${ }^{(4)}$. Assim, pensar o cuidado à pessoa com AVE implica o ser e fazer do enfermeiro para além da dimensão racional e assistencialista, que se limita às manifestações físicas, contemplando as múltiplas dimensões do ser cuidado. Nesse processo, a família torna-se presença indispensável a ser evocada.

Como referido, o envolvimento, o carinho e o apoio dos familiares são fundamentais no enfrentamento da doença e determinantes nos resultados do processo de reabilitação, contribuindo positivamente para a saúde do ser cuidado(6). É cada vez mais comum o manejo das incapacidades geradas pelo AVE no contexto familiar. Frequentemente a família passa a ser prestadora direta dos cuidados domiciliares e necessita estar preparada para esse fim, ser vista como um ente a ser cuidado. É preciso proporcionar-lhe suporte não apenas para cuidar do familiar, mas, sobretudo para enfrentar, compreender e compartilhar a situação de adoecimento(7).

Mediante a necessidade de melhorar a qualidade do cuidado em situações de AVE, surgiu o interesse para se estudar o cuidado de enfermagem a pessoas acometidas pela doença no âmbito nacional. Decidiu-se, então, averiguar o conhecimento acerca da produção científica 
no adoecimento por AVE em língua portuguesa, no intuito de se avaliar na literatura brasileira lacunas existentes, com o propósito de subsidiar futuras investigações na prática clínica de enfermagem. A escolha por estudos em língua portuguesa justifica-se ainda, por se tratar de produções que podem ser consultadas de forma rápida e fácil pelos enfermeiros assistenciais no esclarecimento de dúvidas, muitas vezes, reforçando a tomada de decisão e despertando a reflexão para a ação com fundamento em situações semelhantes vivenciadas no Brasil.

Desse modo, o presente estudo objetivou analisar o conhecimento produzido e divulgado na base de dados LILACS, acerca do cuidado de enfermagem no processo de adoecimento por AVE.

\section{METODOLOGIA}

Trata-se de uma revisão integrativa acerca do cuidado à saúde de pessoas no processo de adoecimento por AVE. Esse tipo de estudo é definido como método que permite a busca, a avaliação crítica e a síntese das evidências disponíveis do tema investigado, sendo o seu produto final o estado atual do conhecimento na implementação de intervenções efetivas na assistência à saúde ${ }^{(1)}$. As conclusões de estudos anteriores são sumarizadas com vistas a formular inferências, identificação de lacunas que direcionam futuras pesquisas e oferecem subsídios que servirão de suporte para a tomada de decisão e melhoria da prática clínica ${ }^{(1,8)}$. Ademais, tem o potencial de construir conhecimento em enfermagem, produzindo um saber fundamentado e uniforme para os enfermeiros realizarem uma prática clínica de qualidade; pode ainda reduzir alguns obstáculos da utilização do conhecimento científico, tornando os resultados de pesquisas mais acessíveis, uma vez que em um único estudo o leitor tem acesso a diversas pesquisas realizadas, ou seja, o método permite agilidade na divulgação do conhecimento( ${ }^{(9-10)}$.

Para elaborar uma revisão integrativa relevante apta a subsidiar a implementação de intervenções eficazes no cuidado aos pacientes, de acordo com o método, as etapas a serem adotadas devem estar claramente

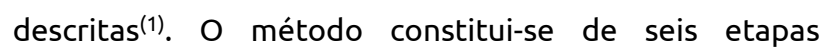
expostas a seguir:
Primeira etapa: identificação do tema e seleção da hipótese ou questão de pesquisa para a elaboração da revisão integrativa

Etapa de formulação de hipóteses ou questão de pesquisa considerada relevante para a saúde e para a enfermagem(11). Na ótica dos estudiosos, a primeira etapa é norteadora para a condução de uma revisão integrativa bem elaborada(1). A questão norteadora da presente revisão foi: "Como o cuidado no contexto de adoecimento por AVE vem sendo apresentado nas pesquisas produzidas pela enfermagem brasileira e divulgadas em periódicos nacionais?".

Como a questão de pesquisa é bem delimitada pelo revisor, os descritores ou palavras-chave são facilmente identificados para a execução da busca dos estudos(12). Neste estudo, utilizaram-se os termos "cuidado" e "acidente vascular encefálico", mediados pelo operador booleano "and".

\section{Segunda etapa: estabelecimento de critérios para inclusão e exclusão de estudos/ amostragem ou busca na literatura}

Após a escolha do tema pelo revisor e a formulação da questão de pesquisa, inicia-se a busca nas bases de dados para identificação dos estudos a serem incluídos na revisão. Neste processo, a internet é uma ferramenta importante, pois as bases de dados possuem acesso eletrônico(1). Realizou-se uma busca de artigos publicados disponíveis na base de dados LILACS (Literatura Latino-Americana e do Caribe em Ciências da Saúde). Nesta fase são estabelecidos os critérios de inclusão/exclusão dos estudos para dar início à busca na literatura. Pesquisados somente em periódicos brasileiros, a busca dos estudos ocorreu em novembro de 2011, pautada nos critérios a seguir:

- Critérios de inclusão: artigos contendo os termos "cuidado" e "acidente vascular encefálico," independente do método de pesquisa utilizado; publicação em língua portuguesa; disponibilidade de texto completo do artigo online; ano de publicação no período de 2000 a 2011.

- Critério de exclusão: não apresentar como temática o cuidado na situação de adoecimento por AVE; artigos com outras temáticas que não 
versavam sobre o cuidado na situação de adoecimento por AVE.

Encontrou-se um total de 26 artigos científicos. Destes, seis foram excluídos, pois quatro artigos não trabalhavam a temática do estudo, e dois estavam repetidos. Assim, a amostra da revisão integrativa acerca do cuidado no adoecimento por AVE compôs-se de 20 publicações, que atendiam aos critérios estabelecidos.

Terceira etapa: definição das informações a serem extraídas dos estudos selecionados/categorização dos estudos

Esta etapa tem o objetivo de organizar e sumarizar as informações de maneira concisa e de fácil manejo. Nela, o revisor deverá organizar e sumarizar as informações de maneira concisa, formando um banco de dados de fácil acesso e manejo. Geralmente as informações abrangem a amostra do estudo (sujeitos), os objetivos, a metodologia empregada, resultados e as principais conclusões de cada estudo(12).

Com esta finalidade, construiu-se um formulário para cada artigo semelhante a um banco de dados, contendo informações relativas aos periódicos como título da pesquisa, nomes dos autores, ano, objetivo, delineamento metodológico, síntese resultados e níveis de evidência.

\section{Quarta etapa: avaliação dos estudos incluídos na revisão integrativa}

Esta fase efetuou-se por meio de leituras exploratória, seletiva, analítica e interpretativa dos textos, bem como do banco de dados construído. A análise dos dados teve por base a literatura pertinente. Como proposto, os estudos selecionados devem ser analisados detalhadamente, de forma crítica(1), procurando explicações para resultados diferentes ou conflitantes nos diferentes estudos.

Em virtude do tipo de estudo desenvolvido, verificou-se nível de evidência baixo. Como identificado, 19 artigos possuíam nível de evidência quatro e um evidência cinco. Em 11 publicações observou-se delineamento metodológico qualitativo, cinco foram estudos quantitativos e descritivos, três foram revisão de literatura e um relato de experiência.

\section{Quinta etapa: Interpretação dos resultados}

A quinta etapa da revisão integrativa constitui-se da definição das informações extraídas dos estudos selecionados, utilizando um instrumento para reunir e sintetizar as informações-chave ${ }^{(13)}$.

\section{Sexta etapa: Publicação e comunicação dos achados}

A sexta fase da revisão, na qual se deve publicar e comunicar os achados, tornando acessíveis os procedimentos adotados, objetivou analisar o conhecimento produzido e divulgado em bases de dados da área de saúde acerca do cuidado de enfermagem no processo de adoecimento por AVE. Compuseram a amostra 20 estudos disponibilizados na base de dados LILACS, do período de 2000 a 2011. Procurou-se conhecer os objetivos, os resultados e os níveis de evidência. Os autores constituíram-se principalmente de enfermeiros; apenas dois artigos foram elaborados por outros profissionais de saúde, fisioterapeuta e psicólogo.

\section{RESULTADOS E DISCUSSÃO}

Identificaram-se 20 estudos decorrentes do entrecruzamento dos termos "acidente vascular encefálico" e "cuidado". A síntese dos dados extraídos dos estudos apresenta-se de forma descritiva no Quadro 1. 
Quadro 1: Distribuição dos estudos com relação ao título, autores, objetivos, delineamento metodológico, síntese dos resultados e nível de evidência.

\begin{tabular}{|c|c|c|c|c|c|c|}
\hline Título & Autores & Ano & Objetivos & $\begin{array}{l}\text { Delineamento } \\
\text { metodológico }\end{array}$ & Síntese dos resultados & $\begin{array}{l}\text { Níveis de } \\
\text { evidencia }\end{array}$ \\
\hline $\begin{array}{l}\text { 1. Atuação da enfermagem no auto } \\
\text { cuidado e reabilitação de pacientes } \\
\text { que sofreram acidente vascular } \\
\text { encefálico. }\end{array}$ & $\begin{array}{l}\text { Lesmann, JC } \\
\quad \text { et.al. }\end{array}$ & 2011 & $\begin{array}{l}\text { Relatar assistência de Enfermagem } \\
\text { ao indivíduo acometido pelo AVE. }\end{array}$ & $\begin{array}{l}\text { Estudo descritivo; relato de } \\
\text { experiência }\end{array}$ & $\begin{array}{l}\text { Descreve os cuidados de enfermagem para } \\
\text { redução dos danos e incapacidades. }\end{array}$ & 5 \\
\hline $\begin{array}{l}\text { 2. Condutas para prevenção de } \\
\text { quedas de pacientes com acidente } \\
\text { vascular encefálico. }\end{array}$ & $\begin{array}{l}\text { Oliveira, ARS et } \\
\text { al. }\end{array}$ & 2011 & $\begin{array}{c}\text { Analisar a prevenção de quedas de } \\
\text { pacientes com AVE. }\end{array}$ & $\begin{array}{l}\text { Abordagem quantitativa; } \\
\text { estudo descritivo }\end{array}$ & $\begin{array}{l}\text { Foram identificados seis comportamentos } \\
\text { para prevenção de quedas segundo a } \\
\text { Nursing Outcomes Classification. }\end{array}$ & 4 \\
\hline $\begin{array}{l}\text { 3. Cuidados domiciliares ao idoso } \\
\text { que sofreu um acidente vascular } \\
\text { cerebral. }\end{array}$ & $\begin{array}{l}\text { Pedreira, LC; } \\
\text { Lopes, RLM. }\end{array}$ & 2010 & $\begin{array}{c}\text { Identificar a produção do } \\
\text { conhecimento do idoso cuidado no } \\
\text { domicílio. }\end{array}$ & Estudo bibliográfico & $\begin{array}{l}\text { Os achados principais relacionaram-se ao } \\
\text { cuidador, aspectos clínicos e } \\
\text { epidemiológicos da doença. }\end{array}$ & 4 \\
\hline $\begin{array}{l}\text { 4. Cuidado de enfermagem ao } \\
\text { paciente com acidente vascular } \\
\text { encefálico: revisão integrativa. }\end{array}$ & $\begin{array}{l}\text { Bianchini, SM; } \\
\text { Galvão, CM; } \\
\text { Arcuri, EAM. }\end{array}$ & 2010 & $\begin{array}{c}\text { Analisar o conhecimento sobre o } \\
\text { cuidado de enfermagem na fase } \\
\text { aguda do AVE. }\end{array}$ & Estudo Bibliográfico & $\begin{array}{l}\text { Foram abordados aspectos importantes no } \\
\text { cuidado hospitalar do doente com AVE na } \\
\text { fase aguda. }\end{array}$ & 4 \\
\hline $\begin{array}{l}\text { 5. Características de pacientes } \\
\text { disfágicos em serviço de } \\
\text { atendimento domiciliar público. }\end{array}$ & $\begin{array}{l}\text { Paixão, CT; Silva, } \\
\text { LD. }\end{array}$ & 2010 & $\begin{array}{l}\text { Caracterizar pacientes disfágicos } \\
\text { por AVE }\end{array}$ & $\begin{array}{l}\text { Abordagem quantitativa; } \\
\text { estudo descritivo }\end{array}$ & $\begin{array}{l}\text { A idade média foi } 73,6 \text { anos, } 76,4 \% \text { eram } \\
\text { mulheres; todos eram hipertensos e metade } \\
\text { diabéticos. A disfagia foi maior para líquidos. }\end{array}$ & 4 \\
\hline $\begin{array}{l}\text { 6. A vivência do cuidador familiar de } \\
\text { vítima de Acidente Vascular } \\
\text { Encefálico: uma abordagem } \\
\text { interacionista. }\end{array}$ & $\begin{array}{l}\text { Machado, ALG; } \\
\text { Jorge, MSB; } \\
\text { Freitas, CHA. }\end{array}$ & 2009 & $\begin{array}{l}\text { Compreender a vivência do cuidador } \\
\text { familiar de pessoas com AVE, no } \\
\text { domicilio. }\end{array}$ & $\begin{array}{l}\text { Abordagem qualitativa. } \\
\text { Utilizou-se o referencial } \\
\text { teórico do interacionismo } \\
\text { simbólico. }\end{array}$ & $\begin{array}{c}\text { Apresenta o significado de tornar-se } \\
\text { cuidador, as transformações ocorridas na } \\
\text { vida após a doença e as atividades diárias } \\
\text { dos cuidadores. }\end{array}$ & 4 \\
\hline $\begin{array}{l}\text { 7. A problemática do cuidador } \\
\text { familiar do portador de acidente } \\
\text { vascular cerebral. }\end{array}$ & $\begin{array}{c}\text { Andrade, LM et } \\
\text { al. }\end{array}$ & 2009 & $\begin{array}{l}\text { Identificar as dificuldades do } \\
\text { cuidador familiar para o cuidado } \\
\text { domiciliar. }\end{array}$ & $\begin{array}{l}\text { Abordagem quantitativa; } \\
\text { estudo descritivo }\end{array}$ & $\begin{array}{c}\text { As dificuldades relacionaram-se com } \\
\text { atividade como alimentação, administração } \\
\text { de medicamentos e dúvidas quanto à } \\
\text { complicações após a alta. }\end{array}$ & 4 \\
\hline $\begin{array}{l}\text { 8. O cuidado domiciliar de idosos } \\
\text { acometidos por acidente vascular } \\
\text { cerebral: cuidadores familiares. }\end{array}$ & Souza, CB et al. & 2009 & $\begin{array}{l}\text { Identificar os cuidados realizados } \\
\text { por cuidadores familiares. }\end{array}$ & $\begin{array}{l}\text { Abordagem quantitativa; } \\
\text { estudo descritivo }\end{array}$ & $\begin{array}{l}\text { Os cuidados relacionaram-se com a } \\
\text { alimentação, administração de } \\
\text { medicamentos e acompanhamento às } \\
\text { consultas. }\end{array}$ & 4 \\
\hline $\begin{array}{l}\text { 9. Disseminação de informações em } \\
\text { ações específicas para o acidente } \\
\text { vascular cerebral. }\end{array}$ & Leite, SMA. & 2009 & $\begin{array}{l}\text { Analisar as estratégias recomendas } \\
\text { pela OMS para disseminação de } \\
\text { informações para redução de novos } \\
\text { casos de AVE. }\end{array}$ & Revisão bibliográfica. & $\begin{array}{l}\text { Os resultados mostram que são poucas as } \\
\text { estratégias encontradas no Brasil com foco } \\
\text { específico no cuidado ao AVE. }\end{array}$ & 5 \\
\hline $\begin{array}{l}\text { 10. Entre a liberdade e a reclusão: o } \\
\text { apoio social como componente da } \\
\text { qualidade de vida do binômio } \\
\text { cuidador familiar-pessoa } \\
\text { dependente. }\end{array}$ & $\begin{array}{l}\text { Bocchi, SCM; } \\
\text { Ângelo, M. }\end{array}$ & 2008 & $\begin{array}{l}\text { Compreender a experiência de } \\
\text { cuidadores familiares sobre o apoio } \\
\text { social recebido na reabilitação } \\
\text { domiciliar. }\end{array}$ & $\begin{array}{l}\text { Abordagem qualitativa. } \\
\text { Utilizou-se a Grounded } \\
\text { Theory e o interacionismo } \\
\text { simbólico de Charon. }\end{array}$ & $\begin{array}{l}\text { O apoio social contribui para autonomia do } \\
\text { doente e qualidade de vida de cuidadores. }\end{array}$ & 4 \\
\hline $\begin{array}{l}\text { 11. Assistência de enfermagem à } \\
\text { pessoa com acidente vascular } \\
\text { cerebral. }\end{array}$ & $\begin{array}{l}\text { Gomes, SR; } \\
\text { Senna, M. }\end{array}$ & 2008 & $\begin{array}{l}\text { Analisar os conhecimentos descritos } \\
\text { na literatura sobre os cuidados de } \\
\text { enfermagem a pacientes com AVE. }\end{array}$ & Estudo Bibliográfico & $\begin{array}{l}\text { Descreve as cinco etapas no adoecimento } \\
\text { por AVE, considerando as ações de } \\
\text { enfermagem pertinentes a cada uma. }\end{array}$ & 5 \\
\hline
\end{tabular}




\begin{tabular}{|c|c|c|c|c|c|c|}
\hline Título & Autores & Ano & Objetivos & $\begin{array}{l}\text { Delineamento } \\
\text { metodológico }\end{array}$ & Síntese dos resultados & $\begin{array}{l}\text { Niveis de } \\
\text { evidencia }\end{array}$ \\
\hline $\begin{array}{l}\text { 12. Desarrumou tudo! o impacto do } \\
\text { acidente vascular encefálico na } \\
\text { família. }\end{array}$ & $\begin{array}{c}\text { Brito, ES; } \\
\text { Rabinovich, EP. }\end{array}$ & 2008 & $\begin{array}{c}\text { Compreender as dificuldades } \\
\text { estruturais, socioeconômicas e } \\
\text { emocionais da família de pacientes } \\
\text { com AVE. }\end{array}$ & $\begin{array}{l}\text { Abordagem qualitativa; } \\
\text { Análise de Discurso do } \\
\text { Sujeito Coletivo }\end{array}$ & $\begin{array}{l}\text { A família passa por um processo de } \\
\text { transformação, implicando em } \\
\text { reorganização e adoção de estratégias de } \\
\text { enfrentamento. }\end{array}$ & 4 \\
\hline $\begin{array}{l}\text { 13. Cuidador Familiar de Seqüelados } \\
\text { de Acidente Vascular Cerebral: } \\
\text { Significado e Implicações }\end{array}$ & $\begin{array}{l}\text { Mendonça, FF; } \\
\text { Garanhani, ML; } \\
\text { Martins, VL. }\end{array}$ & 2008 & $\begin{array}{c}\text { Analisar o significado e as } \\
\text { implicações de se tornar cuidador } \\
\text { de um indivíduo seqüelado de AVC. }\end{array}$ & $\begin{array}{l}\text { Abordagem qualitativa. } \\
\text { Análise de conteúdo }\end{array}$ & $\begin{array}{l}\text { Ser cuidador familiar é um fenômeno } \\
\text { complexo, que gera nos sujeitos } \\
\text { sentimentos de alegria e felicidade } \\
\text { concomitantes aos sentimentos de medo, } \\
\text { ansiedade e revolta. }\end{array}$ & 4 \\
\hline $\begin{array}{c}\text { 14. A família também adoece!: } \\
\text { mudanças secundárias à ocorrência } \\
\text { de um acidente vascular encefálico } \\
\text { na família }\end{array}$ & $\begin{array}{c}\text { Brito, ES; } \\
\text { Rabinovich, EP. }\end{array}$ & 2008 & $\begin{array}{l}\text { Compreender o impacto do AVE na } \\
\text { família de pacientes vítimas de } \\
\text { (AVE). }\end{array}$ & $\begin{array}{l}\text { Abordagem qualitativa. } \\
\text { Análise de Discurso do } \\
\text { Sujeito Coletivo }\end{array}$ & $\begin{array}{l}\text { Constatou-se que a ocorrência do AVE é uma } \\
\text { experiência marcada por transformações no } \\
\text { cotidiano familiar. }\end{array}$ & 4 \\
\hline $\begin{array}{l}\text { 15. Cliente com acidente vascular } \\
\text { cerebral e as interfaces da } \\
\text { assistência de enfermagem para a } \\
\text { reabilitação }\end{array}$ & $\begin{array}{l}\text { Gomes, SR; } \\
\text { Senna, M. }\end{array}$ & 2008 & $\begin{array}{l}\text { Investigar doentes com AVE, } \\
\text { caracterizando o perfil } \\
\text { sóciodemografico. }\end{array}$ & $\begin{array}{l}\text { Abordagem quantitativa; } \\
\text { estudo descritivo }\end{array}$ & $\begin{array}{l}\text { Os resultados foram analisados pelo } \\
\text { refencial teórico de Hinds, Chaves e Cypress. }\end{array}$ & 4 \\
\hline $\begin{array}{l}\text { 16. Diagnóstico de enfermagem em } \\
\text { pacientes internados por acidente } \\
\text { vascular encefálico. }\end{array}$ & Cavalcante, TF. & 2008 & $\begin{array}{l}\text { Analisar o perfil de diagnósticos de } \\
\text { enfermagem em pacientes com } \\
\text { AVE. }\end{array}$ & $\begin{array}{l}\text { Abordagem quantitativa; } \\
\text { estudo descritivo }\end{array}$ & $\begin{array}{l}\text { O AVE isquêmico predominou no grupo; os } \\
\text { pacientes apresentaram uma mediana de } \\
\text { dez diagnósticos de enfermagem. }\end{array}$ & 4 \\
\hline $\begin{array}{l}\text { 17. Educação em saúde e família: o } \\
\text { cuidado ao paciente, vítima de } \\
\text { acidente vascular cerebral. }\end{array}$ & $\begin{array}{l}\text { Chagas, NR; } \\
\text { Macêdo, AR. }\end{array}$ & 2004 & $\begin{array}{l}\text { Identificar o conhecimento dos } \\
\text { familiares de pacientes com AVC } \\
\text { sobre a doença e os cuidados. }\end{array}$ & $\begin{array}{l}\text { Abordagem qualitativa; } \\
\text { teoria do autocuidado de } \\
\text { Dorothea Elizabeth Orem. }\end{array}$ & $\begin{array}{l}\text { Os familiares possuíam baixo conhecimento } \\
\text { sobre a doença e os cuidados domiciliares. }\end{array}$ & 4 \\
\hline $\begin{array}{c}\text { 18. Processo de cuidar de idosos } \\
\text { com acidente vascular encefálico: } \\
\text { sentimentos dos familiares } \\
\text { envolvidos }\end{array}$ & $\begin{array}{l}\text { Lavinsky, AE; } \\
\text { Vieira, TT. }\end{array}$ & 2004 & $\begin{array}{l}\text { Identificar os sentimentos dos } \\
\text { familiares envolvidos no cuidar } \\
\text { desses idosos com AVE. }\end{array}$ & $\begin{array}{l}\text { Abordagem qualitativa. } \\
\text { Utilizou-se a Teoria das } \\
\text { representações Sociais }\end{array}$ & $\begin{array}{l}\text { Sobressaíram sentimentos como amor, } \\
\text { tristeza, pena, culpa, angústia e insegurança. }\end{array}$ & 4 \\
\hline $\begin{array}{l}\text { 19. Cuidar de pessoa incapacitada } \\
\text { por acidente vascular cerebral no } \\
\text { domicílio: o fazer do cuidador } \\
\text { familiar. }\end{array}$ & $\begin{array}{l}\text { Perlini, NMOG; } \\
\text { Faro, ACM }\end{array}$ & 2005 & $\begin{array}{c}\text { Descrever as atividades do cuidador } \\
\text { familiar do doente com AVC no } \\
\text { domicílio. }\end{array}$ & $\begin{array}{c}\text { Abordagem quantitativa; } \\
\text { estudo estatítico descritivo, } \\
\text { analisado pelo epi-info versão } \\
6.04 .\end{array}$ & $\begin{array}{l}\text { Os cuidados relacionaram-se ao grau de } \\
\text { dependência; a necessidade de preparo da } \\
\text { família para a alta hospitalar foi apontada. }\end{array}$ & 4 \\
\hline $\begin{array}{l}\text { 20. Interação cuidador familiar- } \\
\text { pessoa com AVC: autonomia } \\
\text { compartilhada. }\end{array}$ & $\begin{array}{l}\text { Bocchi, SCM; } \\
\text { Ângelo, M }\end{array}$ & 2005 & $\begin{array}{l}\text { Compreender a experiência de } \\
\text { cuidadores familiares acerca do } \\
\text { modo de cuidado adotado. }\end{array}$ & $\begin{array}{l}\text { Abordagem qualitativa. } \\
\text { Utilizou-se a Grounded } \\
\text { Theory e o interacionismo } \\
\text { simbólico de Charon. }\end{array}$ & $\begin{array}{c}\text { Evidenciou-se os processos de retomada da } \\
\text { autonomia da pessoa com AVC e do } \\
\text { cuidador. }\end{array}$ & 4 \\
\hline
\end{tabular}


Em relação aos autores, segundo verificado, os estudos acerca do cuidado no adoecimento por AVE são realizados, principalmente, por enfermeiros, mas outros profissionais como fisioterapeuta e psicólogo também constaram como autores. Isso demonstra que o cuidado, embora perpasse por outras profissões da área de saúde, situa-se na enfermagem ${ }^{(14)}$ como objeto de estudo e cerne da profissão, e por isso tem-se verificado aumento nas produções de enfermagem no tocante à temática cuidado, com o objetivo de contribuir para a estruturação da enfermagem como disciplina científica no campo da saúde.

A análise dos objetivos dos estudos permitiu a observação de que grande parte dos autores buscou compreender a vivência, experiências e sentimentos do cuidador familiar ao assumir o cuidado do doente incapacitado por AVE no domicílio e o impacto da doença na família. Рara tal, utilizaram abordagens e a teoria fundamentada nos $\operatorname{dados}^{(16-17)}$, teoria das representações sociais( ${ }^{(18)}$, o discurso do sujeito

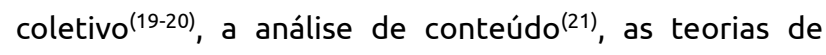
enfermagem ${ }^{(22)}$. Os estudos com recorte quantitativo procuraram caracterizar pacientes vitimados por AVE(2324), descrever as atividades realizadas para o cuidado das pessoas com sequelas de $\operatorname{AVE}^{(25-26)}$, bem como o perfil do cuidador de pessoas acometidos pela doença ${ }^{(25-28)}$. Nesses estudos, observou-se o uso de estatística descritiva com frequências simples e porcentagens. Estes achados demonstram a tendência atual da enfermagem em desenvolver pesquisas qualitativas. As abordagens mencionadas envolvem a totalidade dos seres humanos, buscam a compreensão da experiência humana e entendem a vida como a matriz de relações pessoa-pessoa-ambiente surgidas ao longo do cotidiano $^{(29)}$.

Além dos cuidadores familiares, os estudos investigaram a situação de adoecimento junto a pacientes com AVE e acompanhantes hospitalares de pacientes, independente do grau de parentesco(21-22).

Em todos os estudos, a dependência do doente e a inabilidade рага a execução do autocuidado foram abordadas, e consideradas fator que justificava a intensidade de cuidados que era prestada pelo cuidador.

O estar doente designa a experiência na qual nossas capacidades do dia-a-dia falham; há uma obstrução ao acesso normalmente tido com o meio ao nosso redor. $\mathrm{O}$ corpo é o sinalizador, em regra, que aponta nossas limitações e nossos impedimentos em transitar no mundo de forma usual ${ }^{(30)}$.

A depender da gravidade de comprometimento neurológico, o AVE impõe à pessoa deficiências neurológicas e incapacidades residuais significativas. Entre estas, motora e de locomoção, de comunicação, emocional, cognitivas, visual e auditiva, as quais implicam a perda da autonomia e determinam a necessidade de auxílio de terceiros para a realização de ações cotidianas básicas, principalmente as atividades de vida diária(5,31-33).

Sobressaiu, também, a associação cultural do AVE com morte, invalidez e dependência(16-19,32-33). Outro aspecto enfatizado foi a natureza inesperada da doença que aparece como uma grande ameaça para a pessoa atingida e sua família(15-16,19-20). Consoante os demais artigos deixaram claro, no processo de adoecimento, a família sofre profundo impacto e vivencia momentos de desequilíbrios decorrentes da reorganização da estrutura e dinâmica familiares ${ }^{(19,21)}$. Dados semelhantes foram encontrados em pesquisa desenvolvida com famílias de pessoas adultas dependentes de cuidados físicos $^{(34)}$, na qual a presença inesperada da doença no âmbito familiar configurou-se por si só uma vivência trágica, a exigir a reestruturação do viver da família.

Os artigos sinalizaram a relação de interdependência existente entre a pessoa acometida por AVE e a família(15,17,19-21,26-27). Tal situação explica a repercussão da doença em todos os membros da família. Com a alta hospitalar e o retorno ao lar, essas pessoas passam a ser cuidadas, no domicílio, pela família. Uma nova realidade se instala. Como ressaltado, as mudanças decorrentes do adoecimento são propiciadoras de crises, geram estresse em virtude da quebra da rotina familiar, das distribuições repentinas de papéis, do aumento dos custos financeiros e dos sentimentos antes não experimentados como insegurança em prestar determinados cuidados, embaraço na realização de cuidados íntimos e ressentimento inconsciente pela sobrecarga de trabalho.

De acordo com os estudos, é nesse contexto que emerge a figura do cuidador informal(15,17,19,26-27). Este, na grande maioria dos casos, é alguém da família e, embora, geralmente não tenha formação profissional de saúde, é movido pela boa vontade e pela disponibilidade. Conforme as publicações, cuidar de doentes em casa é uma realidade nos dias atuais ${ }^{(6,19,26)}$. 
Cuidador informal pode ser definido como a pessoa, membro ou não da família, que, com ou sem remuneração, cuida do doente ou dependente no exercício das suas atividades diárias, tais como alimentação, higiene pessoal, medicação de rotina, acompanhamento aos serviços de saúde e demais serviços requeridos no cotidiano, como a ida a bancos ou farmácias, excluídas as técnicas ou procedimentos identificados com profissões legalmente estabelecidas, particularmente na área da enfermagem ${ }^{(35)}$.

Como caracterização do cuidador familiar apresentada nos artigos, constaram as seguintes: cuidadores, na quase totalidade dos casos, do gênero feminino, são filhas ou esposas, casadas, que não exerciam atividades fora de casa, que moravam junto com os pacientes e, em geral, nunca haviam desempenhado essa atividade. Como se depreende, socialmente a tarefa de cuidar é imputada à mulher ${ }^{(15-}$ 17,19-21).

Estudo com cuidadores informais de idosos demonstra que as mulheres solteiras costumam exercer, com maior frequência, o papel de cuidadora, principalmente por não possuírem uma família constituída e terem maior disponibilidade, além de serem mais pressionadas pelos familiares para essa função ${ }^{(36)}$.

Segundo os artigos apontaram, a identidade do cuidador vai sendo construída ao longo do processo de cuidar no ambiente familiar, envolvendo na maioria das vezes proximidade afetiva ${ }^{(21,26)}$. Verificou-se que assumir o papel de cuidador familiar é um fenômeno complexo e a interação doente-cuidador é permeada por sentimentos ambíguos a denotar uma dinâmica na qual os sujeitos experimentam alegria e felicidade concomitantes a medo, ansiedade e revolta, sobretudo quando o doente não possui perspectiva promissora de recuperação dos déficits(15,21,27). Consoante alguns estudos, a função de cuidador representou uma obrigação para muitos participantes dos estudos e fator limitante para sua autorrealização(17-18).

Outro aspecto discutido foi o modo de cuidar assumido pelo cuidador e família. De acordo com as publicações, o fenômeno da dependência pode produzir na família sentimento de superproteção em relação ao familiar. Ademais, como apresentado, este fator retarda a retomada da autonomia do ser cuidado e do cuidador $^{(16-17)}$.

Рara que as ações de cuidado desempenhadas pelo cuidador possam transcorrer com equilíbrio é necessário se considerar sua função como presença implicada e presença em reserva. Na primeira, o cuidador é o sujeito comprometido, atuante, que "faz coisas". Na segunda, deve oferecer ao ser cuidado um ambiente desobstruído, não saturado por presença e afazeres, possibilitando-lhe exercitar sua capacidade de sonhar, brincar, pensar e, mais amplamente, criar o mundo na sua medida e segundo suas possibilidades. O cuidador se retira estrategicamente, se mantém em reserva para convocar à ação, ou seja, dar ensejo à atividade criativa do ser cuidado(37).

Ainda como os estudos relataram, nesse processo de cuidar no domicílio, a presença de rede social de apoio é uma variável interveniente tanto no resgate da autonomia do doente como da qualidade de vida do cuidador, ao conferir a este liberdade para retomar seu plano de vida alterado pelo surgimento da doença.

Como observado, as principais atividades apontadas pelos artigos como desenvolvidas pelos cuidadores estão relacionadas às atividades de vida diária, a exemplo da alimentação, da integridade cutânea, da higiene, das eliminações, da terapêutica, da locomoção e da movimentação do ser cuidado, incluindo o cuidado na prevenção de quedas(25-26,38-39). As atividades instrumentais da vida diária do cuidador, como preparar as refeições, lavar e passar as roupas, limpar a casa e realizar tarefas extradomiciliares ${ }^{(25,27)}$.

Encontrou-se determinadas dificuldades enfrentadas ao se exercer o papel de cuidador familiar que foram apresentadas ${ }^{(19,27)}$. Entre elas, atividades que demandam esforço físico(27); a sobrecarga do cuidador, pois muitos deles, além de cuidarem do seu familiar, trabalham fora e/ou têm filhos e/ou cuidam da casa, ou seja, têm outras atividades no seu cotidiano(20-21); dificuldade na reestruturação dos papéis familiares após o AVE ${ }^{(19,20)}$; falta de conhecimento sobre a doença, sua evolução clínica, complicações e forma adequada de realizar o cuidado(22,25-26). Problemas financeiros foram destacados nesses artigos principalmente por comprometer a continuidade do tratamento de reabilitação, gerando um ciclo vicioso em torno da 
doença: falta de tratamento - agravamento da doença. Assim, a atividade de cuidar torna-se cada vez mais árdua.

Todos os artigos alertaram para a necessidade de instrumentalizar e capacitar a família, logo na instituição hospitalar, no preparo da alta, раra a execução dos cuidados no domicílio. O despreparo técnico do cuidador se reflete na apreensão, angústia e insegurança. Como apontado nos estudos, as informações sobre a doença e sua evolução, bem como o tratamento são superficiais ${ }^{(40)}$, e o conhecimento sobre a doença e seus cuidados vai sendo adquirido pelas próprias experiências do familiar como cuidador informal.

Cabe lembrar, no entanto, que o preparo da família para desenvolver o cuidado no domicílio não pode se constituir num momento pontual, apenas por ocasião da alta hospitalar, no qual inúmeras informações são transmitidas, sem saber se atenderão às demandas reais do cuidador. Com vistas à concretização deste momento, é necessária uma relação entre enfermeiro e cuidador, aberta ao diálogo, de modo que o profissional conheça os sujeitos envolvidos e compreenda a situação de adoecimento, bem como os sentimentos dominantes nas relações familiares.

\section{CONCLUSÃO}

A análise do conjunto dos dados permitiu concluir que a maioria dos estudos objetivou compreender a vivência, experiências e sentimentos do cuidador familiar ao assumir o cuidado do doente incapacitado por AVE e o impacto da doença na família, destacando-se como método a abordagem qualitativa.

As publicações enfocaram a problemática da dependência do doente e a inabilidade para o autocuidado. Com a alta hospitalar e o retorno ao domicílio, coube à família a responsabilidade de cuidar. Tal fato justificou o surgimento do cuidador informal. Este era alguém da família e sem formação profissional de saúde. Pela caracterização do cuidador familiar exposta nos estudos, tratava-se de mulheres, filhas ou esposas, que não exerciam atividades laborais fora de

\section{REFERÊNCIAS}

1. Mendes KDS, Silveira RCCP, Galvão CM. Revisão integrativa: método de pesquisa para incorporação de evidências na saúde e na enfermagem. Texto contexto enfermagem. 2008;17(4):75864. casa, residiam com os pacientes e possuíam envolvimento afetivo. Encarregar-se do papel de cuidador foi uma tarefa complexa permeada por sentimentos ambíguos como alegria e felicidade, concomitante a medo, ansiedade, frustração e revolta. Alguns estudos exibiram a função de cuidador como uma obrigação.

Para cuidar no domicílio, a presença de rede social de apoio foi imprescindível para auxiliar no resgate da autonomia do doente, bem como na qualidade de vida do cuidador, ao permitir liberdade para retomar seu plano de vida alterado pela doença. Entre as dificuldades encontradas pelos cuidadores sobressaíram as seguintes: desgaste físico, sobrecarga pelo acúmulo de tarefas, problemas financeiros, impasses na reestruturação de papéis dentro da família, falta de conhecimento sobre a doença, evolução clínica, complicações e forma adequada de realizar o cuidado.

De modo geral, o cuidado desempenhado pelos cuidadores estava direcionado às atividades de vida diária como a alimentação, a integridade cutânea, a higiene, as eliminações, a terapêutica, a locomoção e a movimentação do ser cuidado; e às atividades instrumentais da vida diária do cuidador, como preparar as refeições, lavar e passar as roupas, limpar a casa e executar tarefas extradomiciliares.

Os estudos chamaram atenção para a necessidade de capacitar as famílias de pacientes de AVE para a realização dos cuidados no domicílio. Alertaram que o despreparo do cuidador é uma realidade geradora de angústia, apreensão e insegurança. Nesse contexto, o enfermeiro é chamado a desempenhar o cuidado no intuito de ensinar a família a cuidar da pessoa com AVE e estimular o autocuidado.

Percebeu-se, a partir da análise dos estudos, a urgência de se pesquisar a situação de adoecimento por AVE sob o prisma dos enfermeiros e dos pacientes, como estratégia a ser utilizada para conhecer a realidade no país, e assim fomentar subsídios para melhorar a qualidade do cuidado de enfermagem a essas pessoas.

2. World Health Oragnization [Internet]. Geneva: Preventing chornic diseases [Cited 2011 jul 07]. A vital investiment: WHO global report. 2005. Availabe from: http:// www.who.int/chp/chronic disease_report/contents/foreword.p $\underline{\mathrm{df}}$ 
3. Sociedade Brasileira de Doenças Cerebrovasculares. Primeiro consenso brasileiro para trombólise no acidente vascular cerebral isquêmico agudo. Arq. Neuropsiquiatr. 2002;60(3A):675-680.

4. Backes DS, Sousa FGM, Mello ALSF, Erdmann AL, Nascimento KC, Lessmann JC. Concepções de cuidado: uma análise das teses apresentadas para um programa de pós-graduação em enfermagem. Texto Contexto Enferm. 2006;15(esp):71-8. 5.Lacerda $A$, Valla VV. As práticas de cuidado integral à saúde como proposta para aliviar o sofrimento. In: Pinheiro R, Mattos RA. Cuidado: as fronteiras da integralidade. Rio de Janeiro: Hucitec: ABRASCO; 2004.p. 148-59.

6.Bocchi, SCM. Vivenciando a sobrecarga ao vir-a-ser um cuidador familiar de pessoa com acidente vascular cerebral (AVC): uma análise do conhecimento. Rev. Latino-am. Enfermagem. 2004;12(1):115-21.

7.Teixeira Paixão C, Silva LD. As incapacidades físicas de pacientes com acidente vascular cerebral: ações de enfermagem. Enfermería Global. 2009;15(1): 01-11.

8.Ganong LH. Integrative reviews of nursing research. Res. Nurs. Health. 1987;10: 1-11.

9.Whittemore R, Knafl K. The integrative review: updated methodology. J. Adv. Nurs. 2005; 52(5):546-53.

10. Whittemore R. Combining evidence in nursing research: methods and implications. Nurs Res. 2005;54(1):56-62. 11.Polit DF, Beck CT. Using research in evidence-based nursing practice. In: Polit DF, Beck CT, editors. Essentials of nursing research. Methods, appraisal and utilization. Philadelphia: Lippincott Williams \& Wilkins; 2006. p.457-94.

12.Broome ME. Integrative literature reviews for the development of concepts. In: Rodgers BL, Knafl KA, editors. Concept development in nursing: foundations, techniques and applications.Philadelphia: W.B Saunders Company; 2000. p.23150.

13.Beyea SC, Nicoll LH. Writing an integrative review. AORN J. 1998;67(4):877-80.

14.Pires D. A enfermagem enquanto disciplina, profissão e trabalho. Rev Bras Enferm. 2009;62(5):739-44.

15.Machado ALG, Jorge MSB, Freitas CHA. A vivência do cuidador familiar de vítima de Acidente Vascular Encefálico: uma abordagem interacionista. Rev. bras. enferm. [Internet]. 2009. [Cited 2011 nov 03];62(2):246-51. Available from: http://www.scielo.br/pdf/reben/v62n2/a12v62n2.pdf 16.Bocchi SCM, Angelo M. Entre a liberdade e a reclusão: o apoio social como componente da qualidade de vida do binômio cuidador familiar-pessoa dependente. Rev. Latino-Am. Enfermagem [Internet]. 2008. [Cited 2011 nov 04];16(1):15-23. Available from: http://www.scielo.br/pdf/rlae/v16n1/pt 02.pdf 17.Bocchi SCM, Ângelo M. Interação cuidador familiar-pessoa com AVC: autonomia compartilhada. Ciência \& saúde coletiva.[Internet]. 2005. [Cited 2011 nov 04]; 10(3): 729-38. Available from:

http://www.scielo.br/pdf/csc/v10n3/a29v10n3.pdf 18.Lavinsky AE, Vieira TT. Processo de cuidar de idosos com acidente vascular encefálico: sentimentos dos familiares envolvidos. Acta Scientiarum. Health Sciences 2004; 26(1):41-45. 19.Brito ES, Rabinovich EP. Desarrumou tudo! O impacto do acidente vascular encefálico na família. Saúde Soc.[Internet]. 2008. [Cited 2011 nov 04];17(2):153-69. Available from: http://www.scielo.br/pdf/sausoc/v17n2/15.pdf 20.Brito ES, Rabinovich EP. A família também adoece!: mudanças secundárias à ocorrência de um acidente vascular encefálico na família. Interface [Internet]. 2008. [Cited 2011 nov 04]:12(27):783-94. Available from:

http://www.scielo.br/pdf/icse/v12n27/a09v1227.pdf 21. Mendonça FF, Garanhani ML, Martins, VL. Cuidador familiar de seqüelados de acidente vascular cerebral: significado e implicações. Physis. (Internet). 2008. [Cited 2011 nov
04]:18(1):143-58. Available from:

http://www.scielo.br/pdf/physis/v18n1/v18n01a09.pdf

22.Chagas NR, Macêdo AR. Educação em saúde e família: o

cuidado ao paciente, vítima de acidente vascular cerebral. Acta

Scientiarum. Health Sciences 2004; 26(1):193-204.

23.Paixão CT, Silva LD. Características de pacientes disfágicos em serviço de atendimento domiciliar público. Rev Gaúcha Enferm.[Internet]. 2010. [Cited 2011 nov 03];31(2):262-9.

Available from:

http://seer.ufrgs.br/RevistaGauchadeEnfermagem/article/view/ $12453 / 10234$

24.Gomes SR, Senna M. Cliente com acidente vascular cerebral e as interfaces da assistência de enfermagem para a reabilitação. Online braz. j. nurs. (Internet). 2008. [Cited 2011 nov 04];7(2). Available from:

http://www.objnursing.uff.br/index.php/nursing/article/view/j.1 676-4285.2008.1420

25.Souza CB, Abreu RNDC, Brito EM, Moreira TMM, Silva LMS, Vasconcelos SMM. O cuidado domiciliar de idosos acometidos por acidente vascular cerebral: cuidadores familiares. Rev. enferm. UERJ.[Internet]. 2009. [Cited 2011 nov 04];17(1): 41-5. Available from: http://files.bvs.br/upload/S/0104-

3552/2009/v17n1/a007.pdf

26.Perlini NMOG, Faro ACM . Cuidar de pessoa incapacitada por acidente vascular cerebral no domicílio: o fazer do cuidador familiar. Rev Esc Enferm USP.[Internet]. 2005. [Cited 2011 nov 04]; 39(2):154-63. Available from:

http://www.scielo.br/pdf/reeusp/v39n2/05.pdf

27.Andrade LM, Costa MFM, Caetano JA, Soares E, Beserra EP. A problemática do cuidador familiar do portador de acidente vascular cerebral. Rev. esc. enferm. USP.[Internet]. 2009.[Cited 2011 nov 04]; 43(1):37-43. Available

from: http://www.scielo.br/pdf/reeusp/v43n1/05.pdf 28.Cavalcante TF. Diagnóstico de enfermagem em pacientes internados por acidente vascular encefálico, em Fortaleza/CE [dissertation]. Fortaleza: Universidade Federal do Ceará/UFC; 2008. 95p.

29.Polit D, Hungler B. Fundamentos de pesquisa em enfermagem: métodos, avaliação e utilização. 5st. ed. Porto Alegre: Artmed; 2004.

30. Waldow RV. Cuidar expressão humanizadora da enfermagem. RJ: Vozes; 2006.

31.Pedreira LC, Lopes RLM. Cuidados domiciliares ao idoso que sofreu Acidente Vascular Cerebral. Rev. bras. enferm. [Internet]. 2010 [Cited 2011 nov 03];63(5):837-840. Available from: http://www.scielo.br/pdf/reben/v63n5/23.pdf

32.Bianchini SM; Galvão CM, Arcuri EAM. Cuidado de enfermagem ao paciente com acidente vascular encefálico: revisão integrativa. Online braz. j. nurs. [Internet]. 2010 [Cited 2011 nov 03]; 9(2). Available from:

http://www.objnursing.uff.br/index.php/nursing/article/view/j.1 676-4285.2010.3112

33.Gomes SR, Senna M. Assistência de enfermagem à pessoa com acidente vascular cerebral. Cogitare enferm. [Internet]. 2008 [Cited 2011 nov 04];13(2):220-26. Available from: http://ojs.c3sl.ufpr.br/ojs2/index.php/cogitare/article/view/124 $86 / 8556$

34.Decesaro MN, Ferraz CA. Desvendando o senso do limite de familiares que convivem com pessoa dependente de cuidados físicos. Rev. Eletr. Enf. [Internet]. 2009 [Cited 2011 jul 12];11(1):23-31. Available from:

http://www.fen.ufg.br/revista/v11/n1/v11n1a03.htm.

35.Portaria n.1395 de 13 de dezembro de 1999. Dispõe sobre a Política Nacional de Saúde do Idoso. Diário Oficial da União (Brasília). 1994;(237-E), Seção 1:20.

36. Nakatani AYK, Souto CCS, Paulette IM, Melo TS, Souza MM. Perfil dos cuidadores informais de idosos com déficit de autocuidado atendidos pelo Programa de Saúde da Família. Rev. 
Eletr. Enf. [Internet]. 2003 [Cited 2011 sep 27];5(1). Available from: http://www.fen.ufg.br/revista/revista5 1/perfil.html. 37.Figueiredo LC. As diversas formas de cuidar: novos ensaios de psicanálise contemporânea. São Paulo: Escuta; 2009.

38.Lessmann JC, Conto F, Ramos G, Borenstein MS, Meirelles BHS. Atuação da enfermagem no autocuidado e reabilitação de pacientes que sofreram Acidente Vascular Encefálico. Rev. bras. enferm. [Internet]. 2011 [Cited 2011 nov 03]; 64(1): 198-202.

Available from:

http://www.scielo.br/pdf/reben/v64n1/v64n1a30.pdf 39. Oliveira ARS, Costa AGS, Sousa VEC, Moreira RP, Araújo TL, Lopes MVO et al. Condutas para prevenção de quedas de pacientes com acidente vascular encefálico. Rev. enferm. UERJ.[Internet]. 2011 [Cited 2011 nov 03];19(1):107-113.

Available from: http://www.facenf.uerj.br/v19n1/v19n1a18.pdf 40.Leite SMA Disseminação de informações em ações específicas para o acidente vascular cerebral, em Rio de Janeiro/RJ [dissertation]. Rio de Janeiro: Escola Nacional de Saúde Pública Sérgio Arouca/Fiocruz; 2009. 83p.

Artigo recebido em 10/08/2011.

Aprovado para publicação em 25/04/2012.

Artigo publicado em 30/09/2012. 